\title{
Nano-montmorillonite-doped lubricating grease exhibiting excellent insulating and tribological properties
}

\author{
Zhengfeng CAO, Yanqiu XIA*, Xiang XI \\ School of Energy Power and Mechanical Engineering, North China Electric Power University, Beijing 102206, China \\ Received: 28 October 2016 / Revised: 13 January 2017 / Accepted: 10 February 2017 \\ (C) The author(s) 2017. This article is published with open access at Springerlink.com
}

\begin{abstract}
Three types of nano-montmorillonite were doped as additives to afford lubricating greases. The physicochemical, insulating, and tribological performances of the obtained lubricating greases were investigated in detail. Furthermore, the tribological action mechanisms were analyzed by high magnification optical microscope, Raman spectroscopy, and energy dispersive X-ray spectroscope (EDS). The results show that the inorganic modification montmorillonite (IOMMT) can significantly increase the number of electron traps in the base grease, leading to excellent insulating performances. Moreover, IOMMT as a novel lubricant additive (1.5 $\mathrm{wt} \% \mathrm{in}$ grease) significantly enhances the friction reducing and anti-wear abilities for steel/steel contact that comprises a unique layered structure to prevent friction between the contact pairs and the protective tribofilm generated by physical adsorption and chemical reaction.
\end{abstract}

Keywords: nano-montmorillonite; insulation; friction and wear

\section{Introduction}

The primary function of lubricating agents as engineering materials is to enhance equipment efficiency, reduce frictional loss, and extend the service life of machines [1-3]. However, since mechanical equipments are used in various fields, they present some special demands apart from excellent friction reducing and anti-wear properties. For instance, the lubricating greases applied in some electrical equipment should possess good conductive capacity [4-6], whereas the space lubricating greases should maintain long-term reliability under high-energy irradiation, high vacuum, and high/low temperature [7-10]. Lubricating grease applied in some electrical devices, such as a cable connector, a battery terminal, or a plug connection, should exhibit high levels of insulation to eliminate discharge and excellent tribological properties to reduce frictional loss generated by frequent operations [11-13]. We have proved in our previous study that the greases synthesized with nanometer $\mathrm{SiO}_{2}$ and
$\mathrm{TiO}_{2}$ have an outstanding insulation and tribological performance [11].

Montmorillonite (MMT) is a type of natural nanometer silicate mineral with a layered structure. It has drawn intensive attention across the industry and academia because of its unique performance, including high strength, large special surface area (SSA), superior insulating property, outstanding adsorption capacity, and novel tribological performances. Furthermore, MMT has a sandwich structure, wherein the upper and lower layers are silicon-oxygen tetrahedrons and the middle layer is aluminum-oxygen octahedron. Moreover, exchangeable cations, such as $\mathrm{Na}^{+}, \mathrm{Mg}^{+}$, and $\mathrm{Al}^{+}$, exist between the layers [14-18]. Due to its unique characteristics of having a nano-scale layered structure and exchangeable cations, MMT can be easily modified and used for various applications. There are two methods to modify MMT: organic modification (OMMT) and inorganic modification (IOMMT). The modified MMT possesses higher SSA, adsorption capacity, and dispersive capacity, and it is widely

* Corresponding author: Yanqiu XIA, E-mail: xiayq@ncepu.edu.cn 
applied in the composite, electrical engineering, and medical fields [19-21]. Pojanavaraphan et al. found that MMT significantly improved the material properties, including the mechanical, rheological, and swelling behavior in aerogel/pre-vulcanized natural rubber composites produced by freezing-drying [22]. Rashmi et al. reported that the epoxy nanocomposite with $5 \mathrm{wt} \%$ OMMT exhibited outstanding wear resistance [23]. Yuan et al. prepared a novel cellulose insulating paper with modified MMT and the breakdown voltage was increased from $50.3 \mathrm{kV}$ to $56.9 \mathrm{kV}$ [24]. Fan et al. investigated the tribological properties of a selflubricating liner based on MMT reinforced phenolic nanocomposites and found that the addition of $2 \mathrm{wt} \%$ OMMT induced the required friction and wear properties [25].

In this study, new types of lubricating greases exhibiting excellent insulating and tribological performances were synthesized with nano-montmorillonite and $\mathrm{SiO}_{2}$. The insulating and tribological performances of the lubricating greases were investigated using an automatic electrical breakdown tester, volume resistivity tester, and a MFT-R4000 reciprocation friction and wear tester. High magnification optical microscopy, Raman spectroscopy, and energy dispersive X-ray spectroscopy (EDS) were also employed to explore the lubricating mechanisms.

\section{Experimental details}

\subsection{Materials}

Based on the Lv's work and our previous article [11, 26, 27], naphthenic oil (25\# Karamay transformer oil) was selected as the base oil, and Table 1 shows its typical characteristics. Polytetrafluoroethylene (PTFE, Dyneon $^{\text {TM }}$ TF9207,) with a density of $2.2 \mathrm{~g} / \mathrm{cm}^{3}$ and $4-\mu \mathrm{m}$ grain size was used as a thickener and analytically pure acetone (Sinopharm Chemical Reagent Co., Ltd.) was used as a polar dispersant. Three types of nanomontmorillonite and nano-SiO${ }_{2}$ were purchased from Haichengxingye Technology Co., Ltd (Shenzhen, China) and DK Nano-technology (Beijing, China), respectively. Table 2 lists the typical characteristics and Fig. 1 shows the Fourier transform infrared spectrum of nano-montmorillonite.
Table 1 Typical characteristics of the naphthenic oil.

\begin{tabular}{lcc}
\hline Item & 25\# Karamay & Standard \\
\hline $\begin{array}{l}\text { Kinematic viscosity }\left(40{ }^{\circ} \mathrm{C}\right) \\
\left(\mathrm{mm}^{2} / \mathrm{s}\right)\end{array}$ & 9.936 & ASTM D445 \\
Density $\left(20{ }^{\circ} \mathrm{C}\right)\left(\mathrm{kg} / \mathrm{m}^{3}\right)$ & 883 & ASTM D4052 \\
AC breakdown voltage & 60 & ASTM D149 \\
$(2.5 \mathrm{~mm}$ gap $)(\mathrm{kV})$ & & \\
Pour point $\left({ }^{\circ} \mathrm{C}\right)$ & -35 & ASTM D97 \\
Flash point $\left({ }^{\circ} \mathrm{C}\right)$ & 145 & ASTM D92 \\
Acid value $(\mathrm{mgKOH} / \mathrm{kg})$ & 0.02 & ASTM D664 \\
Moisture $(\mathrm{mg} / \mathrm{kg})$ & $<30$ & ADTM D6304 \\
\hline
\end{tabular}

Table 2 Main characteristics of the nano-montmorillonite and nano- $\mathrm{SiO}_{2}$.

\begin{tabular}{lcccc}
\hline Item & MMT & OMMT & IOMMT & $\mathrm{SiO}_{2}$ \\
\hline Grain size $(\mathrm{nm})$ & $70-80$ & $70-80$ & $70-80$ & $30-40$ \\
Density $\left(\mathrm{g} / \mathrm{m}^{3}\right)$ & $2.5-3$ & $2.5-3$ & $2.5-3$ & 2.2 \\
Purity $(\mathrm{wt} \%)$ & $98 \%$ & $98 \%$ & $98 \%$ & $98 \%$ \\
SSA $\left(\mathrm{m}^{2} / \mathrm{g}\right)$ & 80 & 320 & 200 & 300 \\
\hline
\end{tabular}

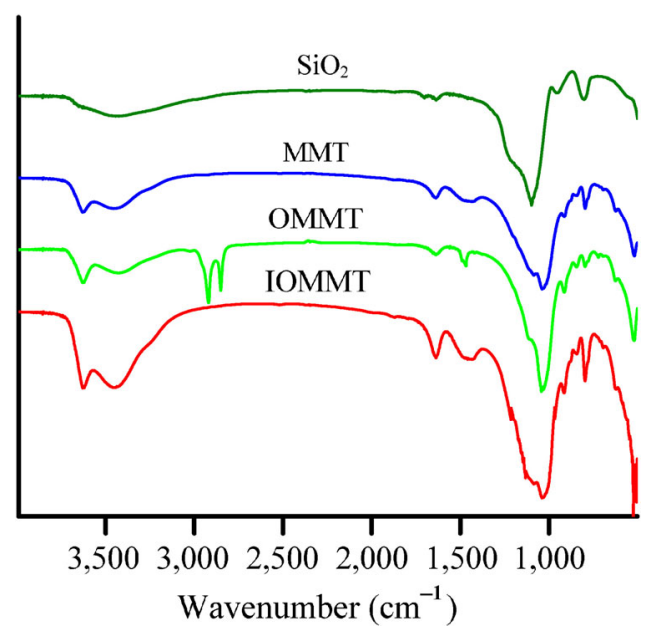

Fig. 1 Fourier transform infrared analysis spectra of the MMT, OMMT, IOMMT and $\mathrm{SiO}_{2}$.

In the curves of the three types of MMT, the peaks from $3,450 \mathrm{~cm}^{-1}$ to $3,650 \mathrm{~cm}^{-1}$ and $1,480 \mathrm{~cm}^{-1}$ to $1,630 \mathrm{~cm}^{-1}$ are assigned to the stretching vibration and bending vibration, respectively, of $\mathrm{H}-\mathrm{O}-\mathrm{H}$. These peaks prove that absorbed water exists between the MMT layers, and crystal water is present as the lattice. The peak at $1,030 \mathrm{~cm}^{-1}$ is attributed to the stretching vibration of $\mathrm{Si}-\mathrm{O}-\mathrm{Si}$, whereas the peak at about $700 \mathrm{~cm}^{-1}$ is assigned to flexural vibration of $\mathrm{Si}-\mathrm{O}$ tetrahedron and $\mathrm{Al}-\mathrm{O}$ octahedron. There are also some typical peaks $\left(520 \mathrm{~cm}^{-1}\right.$ 
and $860 \mathrm{~cm}^{-1}$ ) in the infrared spectra of silicate. These are assigned to the stretching vibrations and flexural vibration of Si-O-Al. In the infrared spectra of the OMMT, the obvious peaks at $2,850-2,920 \mathrm{~cm}^{-1}$ are attributed to the stretching vibration bands of $-\mathrm{CH}_{3}$ and $-\mathrm{CH}_{2}$, respectively $[25,28,29]$. It indicates that organic chains exist between the MMT layers.

\subsection{Preparation of the insulating greases}

The insulating greases were synthesized by the following procedures. First, the base oil (70\%, mass fraction, the same hereafter) was infused into the reaction vessel and agitated at once. Second, the PTFE powder (30\%) and lubricating additives were gently poured into the vessel and fiecely agitated. As the base oil was blended homogenously with the PTFE powder, acetone, whose mass was approximately half of the PTFE, was injected dropwise and agitated for about $30 \mathrm{~min}$ to confirm that the PTFE powder was entirely homo-dispersed within the base oil. Third, the compound was warmed to $80{ }^{\circ} \mathrm{C}$ for another $30 \mathrm{~min}$ to remove acetone. Last, the mixture was cooled to room temperature, and the insulating grease was obtained after three steps of fine grinding/homogenization with a three-roller mill.

\subsection{Characterization of the insulating greases}

The HJC-50 kV automatic 50-Hz electrical breakdown tester (Huayang equipment CO., LTD) was employed to determine the alternating current $(\mathrm{AC})$ breakdown voltage of the insulating greases according to $\mathrm{GB} / \mathrm{T}$ 1408. The electrical breakdown tester consists of plate electrodes, and the distance between the plate electrodes was $1.5 \mathrm{~mm}$ (Fig. 2). The voltage rate was set to $0.2 \mathrm{kV} / \mathrm{s}$. All the tests were conducted at room temperature and each experiment was repeated two times to ensure the

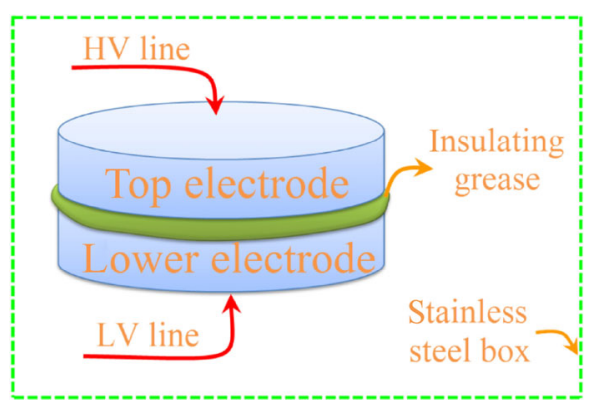

Fig. 2 Diagram of plate electrode structure. reliability of the data, with a third test if the relative error was greater than $5 \%$. The surface volume resistivity of the prepared grease was acquired using GEST-121 surface volume resistivity. The penetration, dropping point, and copper strip tests were conducted according to the national standards, including GB/T 269, GB/T 3498, and GB/T 7326, respectively.

\subsection{Friction and wear tests}

The tribological properties of the insulating greases were investigated using a MFT-R4000 reciprocation friction and wear tester with a ball-on-disk configuration (Fig. 3) at room temperature. The upper ball (commercially available AISI 52100 steel ball, diameter: $5 \mathrm{~mm}$, hardness: $710 \mathrm{HV}$ ) was driven to reciprocally slide against the lower fixed disk ( $\Phi 24 \mathrm{~mm} \times 7.9 \mathrm{~mm}$, AISI 52100 steel, hardness: 590-610 HV) at a stroke of $5 \mathrm{~mm}$. The upper ball and lower disks were cleaned using an ultrasonic cleaner comprising petroleum ether for $10 \mathrm{~min}$ before and after the friction test. About $1 \mathrm{~g}$ of grease was introduced into the reciprocating sliding region. The tribological test parameters, including applied loads and frequencies, range from $50 \mathrm{~N}$ to $200 \mathrm{~N}$ (corresponding to the Hertzian pressure in the range of $1.7-2.7 \mathrm{GPa}$ ) and $2 \mathrm{~Hz}$ to $5 \mathrm{~Hz}$, respectively. The computer connected with the MFT-R4000 tribometer can record the coefficient of friction (COF) automatically. Each tribological test lasts for $30 \mathrm{~min}$ and was repeated three times to guarantee the reliability of the experimental data. After the tribological test, the upper ball and lower blocks were cleansed in petroleum ether for $10 \mathrm{~min}$ utilizing an ultrasonic cleaner. Then, an optical microscope (Olympus, Japan) was employed to acquire the wear width and morphology of the worn

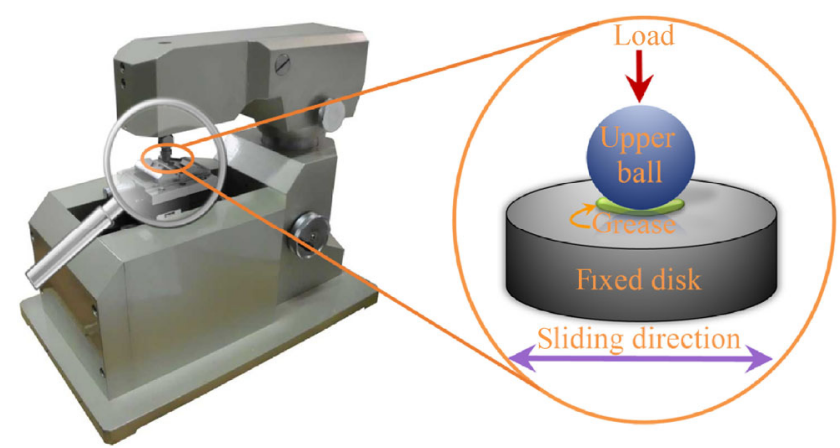

Fig. 3 The MFT-R4000 reciprocation tribometer and contact configuration of the friction pairs. 
surface on the lower disk. A Raman spectroscope with $514 \mathrm{~nm}$ laser excitation (Renishaw, UK) and an energy dispersive X-ray spectroscope (Bruker, Germany) were utilized to evaluate the lubricating mechanisms.

\section{Results}

\subsection{Properties of the insulating greases}

\subsubsection{Physicochemical characteristics of the insulating greases}

The physicochemical parameters of grease can affect the fundamental characteristics. According to the tribological tests shown in the following section, we provided the typical properties of the lubricating greases, containing 1.0\% OMMT, 1.5\% IOMMT, 1.5\% MMT, and $1.0 \% \mathrm{SiO}_{2}$, in Table 3. Compared with the base grease, it was observed that all the additives improved the dropping point and penetration and all the greases possessed good corrosion resistivity. The lubricating grease with $1.0 \%$ OMMT exhibited the lowest penetration among all the greases. The main reason leading to low penetration is that the OMMT has a relatively high SSA and pore volume, which result in a high adsorption capacity. OMMT can restrict the movement of the liquid molecules due to the surface force (which is similar to the intermolecular force). Therefore, the OMMT grease possesses a relatively lower penetration [30].

\subsubsection{Insulating capacity of the prepared greases}

A dielectric conductor loses its dielectric properties under the action of a strong electric field to become an electric conductor. This phenomenon is called

Table 3 Typical properties of the several kinds of insulating greases.

\begin{tabular}{lccc}
\hline Sample & $\begin{array}{c}\text { Dropping } \\
\text { point } \\
\left({ }^{\circ} \mathrm{C}\right)\end{array}$ & $\begin{array}{c}1 / 4 \\
\text { Penetration } \\
(0.1 \mathrm{~mm})\end{array}$ & $\begin{array}{c}\text { Copper } \\
\text { corrosion } \\
(\mathrm{T} 2 \text { copper, } \\
\left.100{ }^{\circ} \mathrm{C}, 24 \mathrm{~h}\right)\end{array}$ \\
\hline Base grease & 332 & 122 & $1 \mathrm{a}$ \\
OMMT $(1.0 \mathrm{wt} \%)$ grease & $>350$ & 81 & $1 \mathrm{a}$ \\
IOMMT $(1.5 \mathrm{wt} \%)$ grease & $>350$ & 94 & $1 \mathrm{a}$ \\
OMMT $(1.5 \mathrm{wt} \%)$ grease & $>350$ & 92 & $1 \mathrm{a}$ \\
$\mathrm{SiO}_{2}(1.0 \mathrm{wt} \%)$ grease & $>350$ & 89 & $1 \mathrm{a}$ \\
\hline
\end{tabular}

dielectric breakdown, and the corresponding voltage is called the breakdown voltage [31,32]. Volume resistivity is the current impedance of the material per unit volume and is used to characterize the material's electrical properties [33, 34]. Therefore, we measured these parameters to characterize the material's insulating performance. Figure 4(a) shows the AC breakdown voltage of the insulating greases with different additive contents. It is clearly observed that the AC breakdown voltage increases with increasing additive content except for 1.5\% OMMT. Compared with the base grease, the AC breakdown voltage of $1.5 \%$ IOMMT grease $(6.54 \mathrm{kV})$ increased by $21 \%$. Figure 4(b) describes the volume resistivity evolution of insulating greases with different additive contents. As the content of the additive increases, the volume resistivity increases; the IOMMT greases possess the highest volume resistivity among all the insulating greases. The volume resistivity of $2.0 \%$ IOMMT grease is about $65 \%$ higher than that of base grease. The AC breakdown voltage and volume resistivity indicate that the IOMMT grease possesses excellent insulating property.

The electron capture theory is used to explain the insulating mechanism [35, 36]. Existing studies have proved that under the effect of the local electric field, the electron can polarize the surrounding molecules to develop charged particles and form a directional movement. After the charged particles move some distance, the electron will detach and reform into new charged particles and continue to move, thereby generating the current. Nevertheless, in the process of movement and developing new charged particles, the energy of the electron gradually decreases. These charged particles can be named as the electron trap $[37,38]$. The addition of nano-montmorillonite can significantly increase the number of electron traps in the base grease, which can reduce the electron transfer rate and energy, leading to a conductive path that is difficult to form $[24,39]$. Thus, the AC breakdown voltage and volume resistivity of the insulating greases are improved. A high trap density is generated by IOMMT in the grease, which makes a positive contribution for high AC breakdown voltage and volume resistivity. 

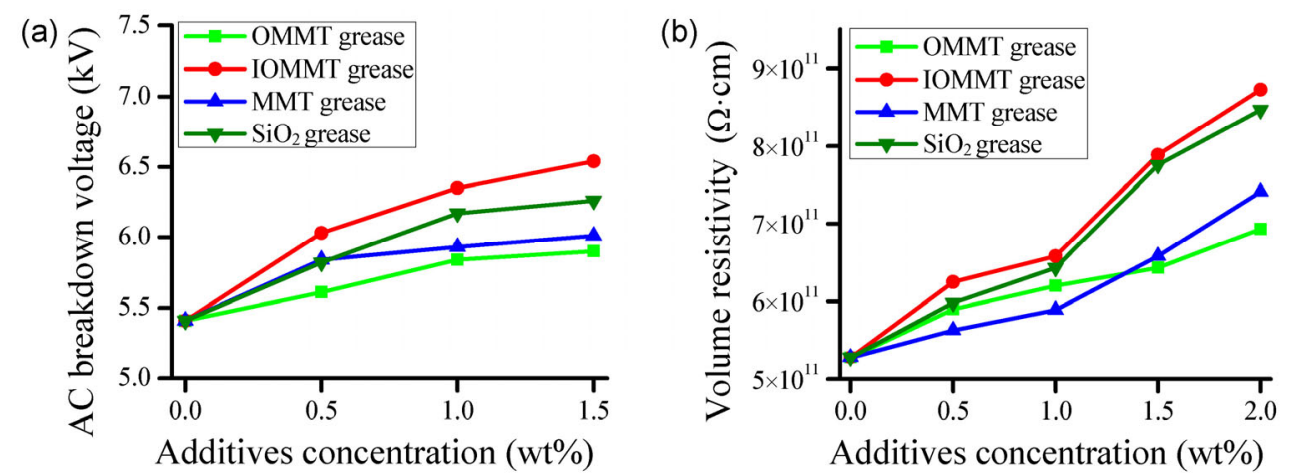

Fig. 4 The AC breakdown voltage (a) and volume resistivity (b) of the prepared insulating greases at different additives concentrations.

\subsection{Tribological test results}

To evaluate the tribological performances of the additives, this article investigated three predominant factors (additive concentration, load, and frequency).

\subsubsection{Effect of additive concentration}

A MFT-R4000 tribometer was employed to investigate the tribological properties of the insulating greases. Figure 5 compares the evolution in the COFs and wear widths for the insulating greases at $50 \mathrm{~N}, 5 \mathrm{~Hz}$, and room temperature (RT). As shown in Fig. 5(a), it is clearly observed that with the increasing concentration of additives, the COFs of all the insulating greases decrease first and then increase. When the concentration of the additives is $1.0 \%, 1.5 \%, 1.5 \%$, and $1.0 \%$, the grease exhibits the best friction reducing property. As shown in Fig. 5(b), the wear width has a similar variation tendency. Compared with the base greases (about $0.19 \mathrm{~mm}$ ), the lubricating grease with $1.0 \%$ OMMT, 1.5\% IOMMT, $1.5 \% \mathrm{MMT}$, and $1.0 \% \mathrm{SiO}_{2}$ exhibited the lowest wear width (about $0.146-0.174 \mathrm{~mm}$ ). For

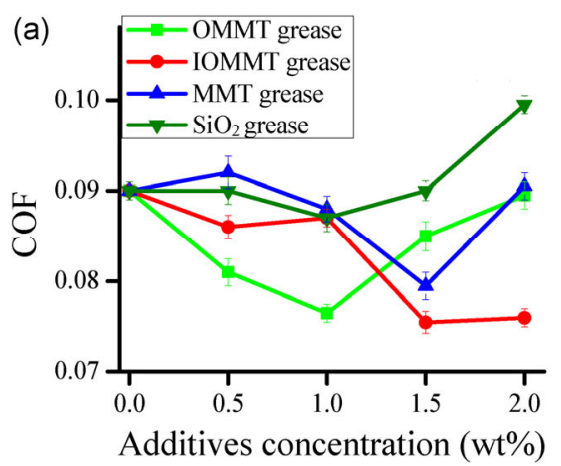

friction reducing and anti-wear performances, the $1.5 \%$ IOMMT grease shows the best tribological performances among all the insulating greases.

Similarly, it can be clearly observed that the best concentration of OMMT in the grease is not the same as that of IOMMT and MMT. This is because the nano-montmorillonite modified by the organics possesses a high SSA and pore volume, due to which OMMT is not uniformly dispersed in the base grease and goes against the formation of the lubrication film during the friction process. Therefore, in the following experiments, the concentration of OMMT, IOMMT, MMT, and $\mathrm{SiO}_{2}$ in the greases was $1.0 \%, 1.5 \%, 1.5 \%$, and $1.0 \%$, respectively.

\subsubsection{Effect of load}

Figure 6 lists the evolution of the COFs and wear widths for the lubricating greases at different loads, $5 \mathrm{~Hz}$, and RT. It is obviously seen that the COFs of the greases increase gradually with the increasing loads, but the IOMMT grease always shows smaller COFs among all the insulating greases under different

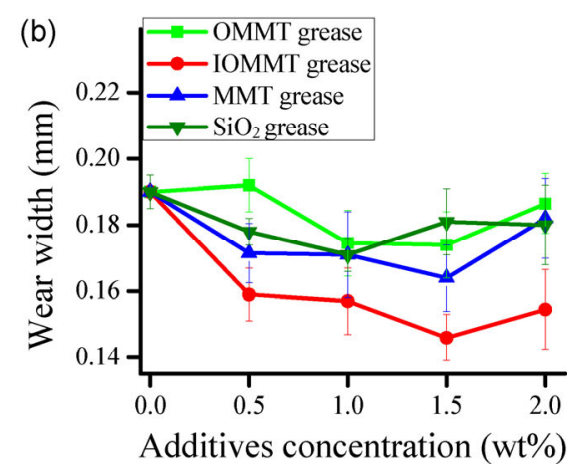

Fig. 5 The average COFs (a) and wear widths change (b) under the lubrication with insulating greases at different additives concentrations at $50 \mathrm{~N}, 5 \mathrm{~Hz}$, and RT. 

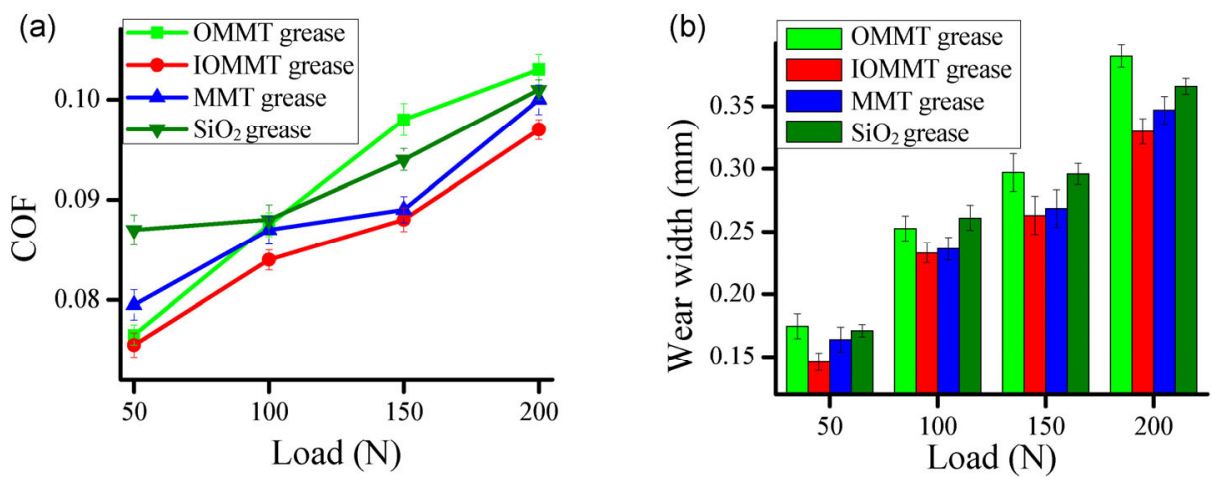

Fig. 6 The average COFs (a) and wear widths change (b) under the lubrication with insulating greases at different loads, $5 \mathrm{~Hz}$, and RT.

loads. As shown in Fig. 6(b), the IOMMT greases show an obviously lower wear width under $50 \mathrm{~N}$ and $200 \mathrm{~N}$. When the loads are $100 \mathrm{~N}$ and $150 \mathrm{~N}$, the wear widths of IOMMT greases (about $0.23 \mathrm{~mm}$ and $0.26 \mathrm{~mm}$ ) are close to that of the MMT greases (about $0.24 \mathrm{~mm}$ and $0.27 \mathrm{~mm}$ ). The results indicate that the IOMMT grease has better tribological properties than other greases.

\subsubsection{Effect of frequency}

Figure 7 displays the COFs and wear widths of insulating greases at different frequencies, $200 \mathrm{~N}$, and RT. As shown in Figs. 7(a) and 7(b), the COFs and wear widths decrease first and then increase with the frequency ranging from $2 \mathrm{~Hz}$ to $5 \mathrm{~Hz}$. At the same time, compared with the other greases, the IOMMT grease exhibited lower COFs and wear widths. The results demonstrate that the IOMMT grease possesses better friction reducing and wear resistance performances than the other lubricating greases.

\subsubsection{Analysis of the worn surfaces}

The surface morphologies of the worn surfaces lubricated with insulating greases are provided in Fig. 8. All the surface morphologies are obtained under the same conditions. The wear width (Fig. 8(b)) and the high magnification morphology (Fig. 8(b)) of the worn surface lubricated with IOMMT grease are the narrowest and smoothest. There are just a few shallow furrows. In contrast, the worn surfaces lubricated with OMMT, MMT, and $\mathrm{SiO}_{2}$ exhibited more dense furrows and larger pits, which are dominated by abrasive and adhesion wear. The images of worn surfaces clearly demonstrate that the IOMMT grease has a better anti-wear performance than that of the other greases.

EDS is an excellent experimental tool to characterize the typical elements on the worn surfaces. To further explore the friction reducing and anti-wear mechanism of the insulating greases, the EDS spectra of the wear scratches lubricated with insulating greases at $200 \mathrm{~N}$ and $5 \mathrm{~Hz}$ are provided in Fig. 9. It can be obviously seen that there are some emblematic elements of nanomontmorillonite, such as $\mathrm{Al}$ and $\mathrm{Si}$, existing on the wear scratches in Figs. 9(a), 9(b), and 9(c). Compared
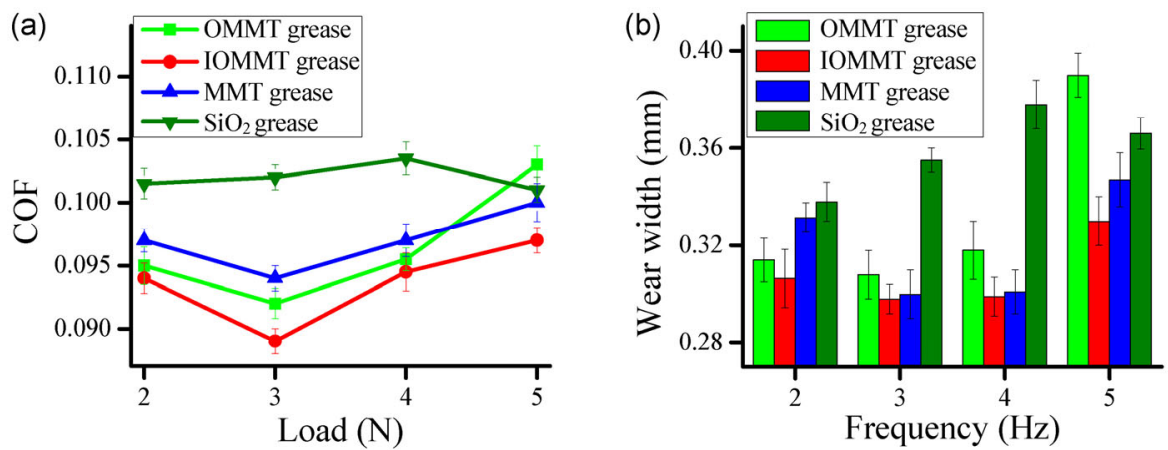

Fig. 7 The average COFs (a) and wear widths change (b) under the lubrication with insulating greases at different frequencies, $200 \mathrm{~N}$, and RT. 

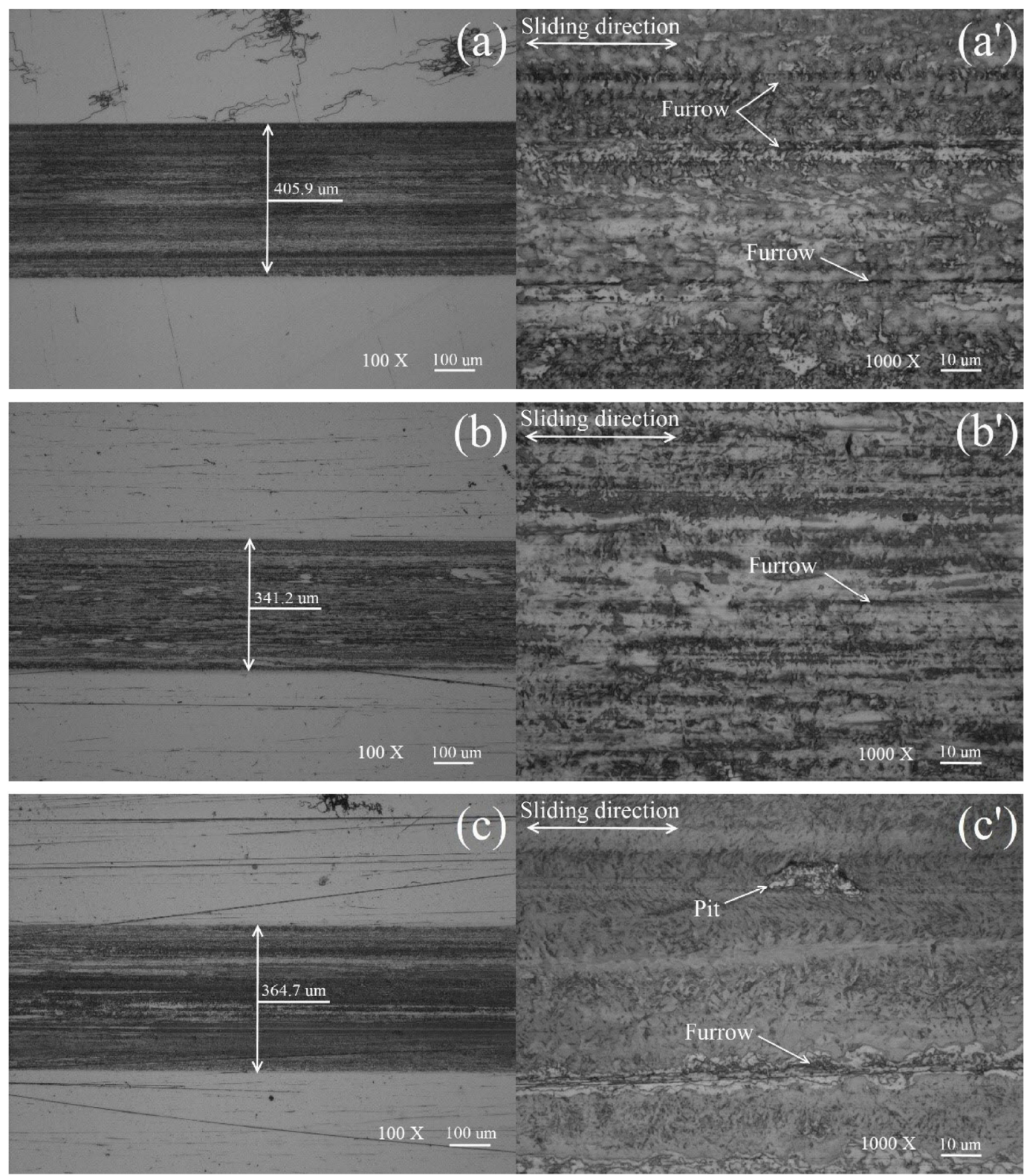

(c')

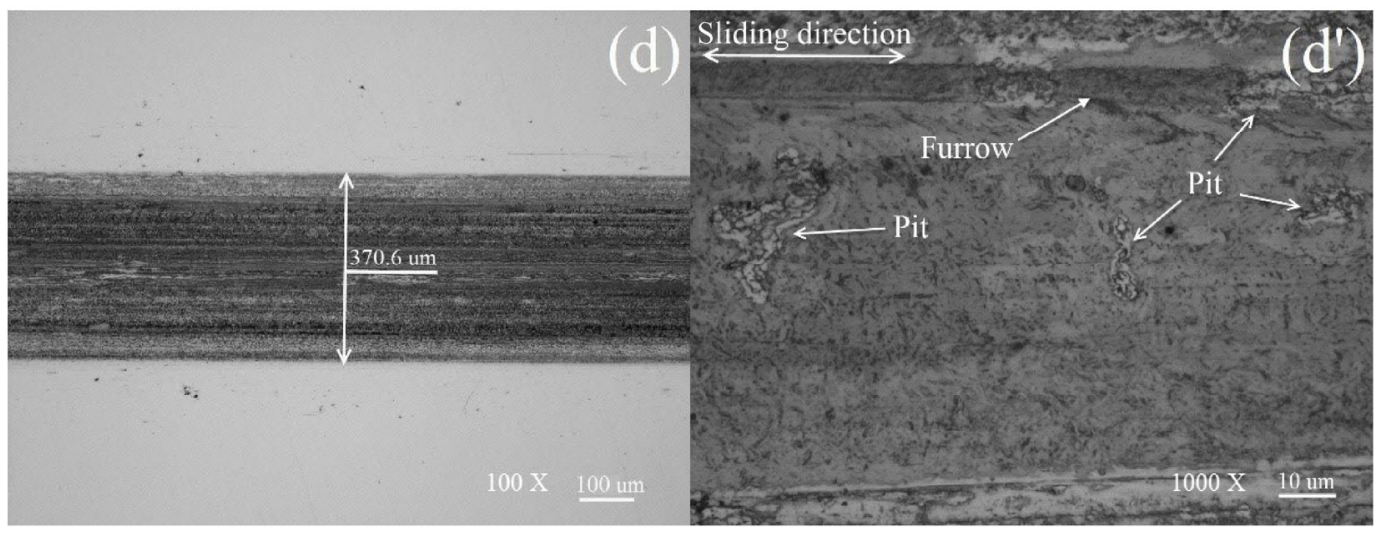

Fig. 8 Morphologies of the worn surfaces lubricated with insulating greases at $200 \mathrm{~N}, 5 \mathrm{~Hz}$, and RT. (a) and (a') OMMT grease, (b) and (b') IOMMT grease, $(c)$ and $\left(c^{\prime}\right)$ MMT grease, $(d)$ and $\left(d^{\prime}\right) \mathrm{SiO}_{2}$ grease. 

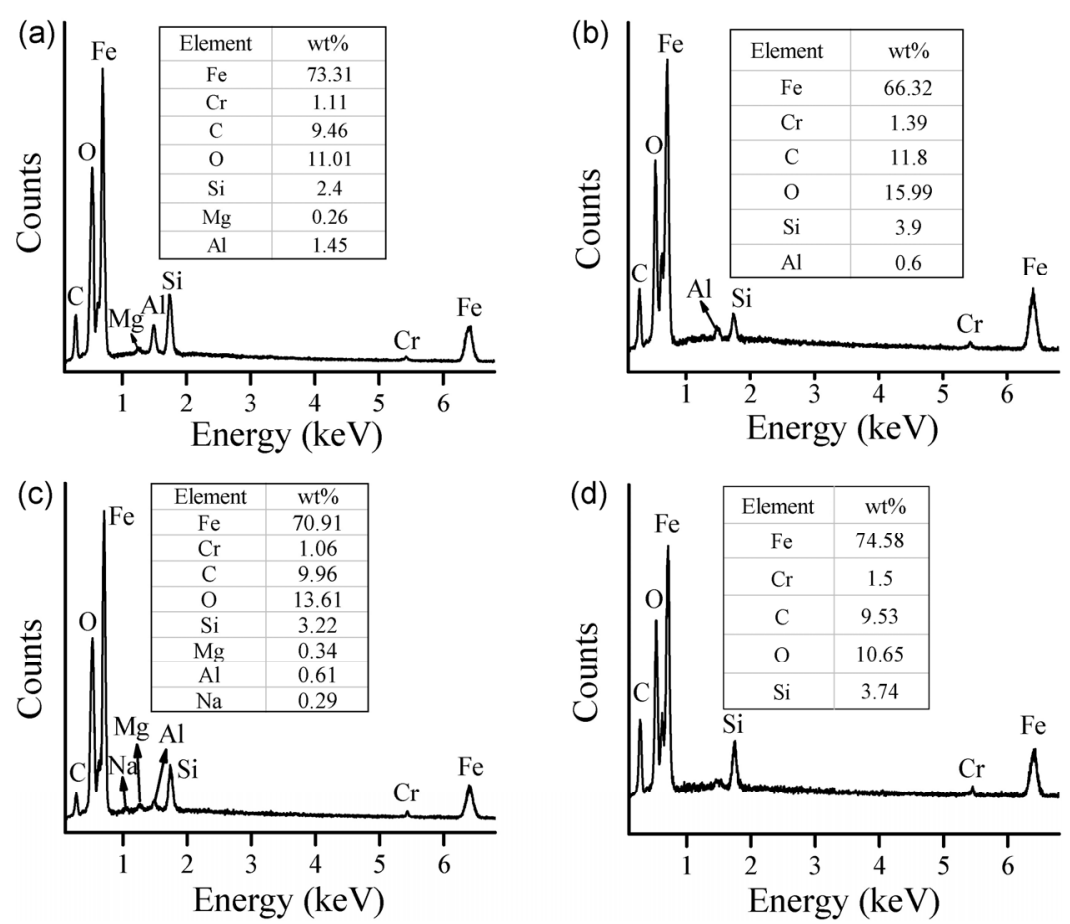

Fig. 9 EDS of the worn surfaces lubricated with insulating greases at $200 \mathrm{~N}, 5 \mathrm{~Hz}$, and RT. (a) OMMT grease, (b) IOMMT grease, (c) MMT grease, and (d) $\mathrm{SiO}_{2}$ grease.

with the wear scratch lubricated with MMT grease (Fig. 9(c)), the sodium and magnesium elements are not observed on the wear scratches lubricated with OMMT and IOMMT greases (Figs. 9(a) and 9(b)), respectively. There is also plenty of $\mathrm{Si}(3.7 \%)$ on the wear scratch lubricated with $\mathrm{SiO}_{2}$ grease (Fig. 9(d)), but the contents of $\mathrm{C}(9.53 \%)$ and $\mathrm{O}(10.65 \%)$ are much lower compared to that of the IOMMT grease. From the EDS spectra, we obtain that the contents of C $(11.8 \%), \mathrm{O}(15.9 \%)$, and $\mathrm{Si}(3.9 \%)$ on the wear scratch lubricated with IOMMT grease are higher than those of the other greases. It is presumed that a sufficiently protective tribofilm is generated on the worn surface in the sliding process. Consequently, the IOMMT grease performs outstanding friction reducing and anti-wear performances.

Figure 10 corresponds to the Raman spectra of IOMMT and the worn surface lubricated with 1.5\% IOMMT grease at $200 \mathrm{~N}, 5 \mathrm{~Hz}$, and RT. The IOMMT is characterized by bands located at $200 \mathrm{~cm}^{-1}, 270 \mathrm{~cm}^{-1}$, $450 \mathrm{~cm}^{-1}, 710 \mathrm{~cm}^{-1}$, and $1,090 \mathrm{~cm}^{-1}[40,41]$. After the tribological test, the disk is cleaned ultrasonically in petroleum ether for $10 \mathrm{~min}$. Then, the worn surface is examined using a Raman microscope. It is obviously seen that these typical peaks of IOMMT exist on the worn surface. At the same time, we also acquire some other bands $\left(224 \mathrm{~cm}^{-1}, 328 \mathrm{~cm}^{-1}, 425 \mathrm{~cm}^{-1}\right.$, and $\left.609 \mathrm{~cm}^{-1}\right)$, which are assigned to various iron oxides $[42,43]$. The Raman test results prove that IOMMT is adsorbed on the worn surface to form an adsorption film and iron oxides are generated on the worn surfaces to form a chemical reaction film.

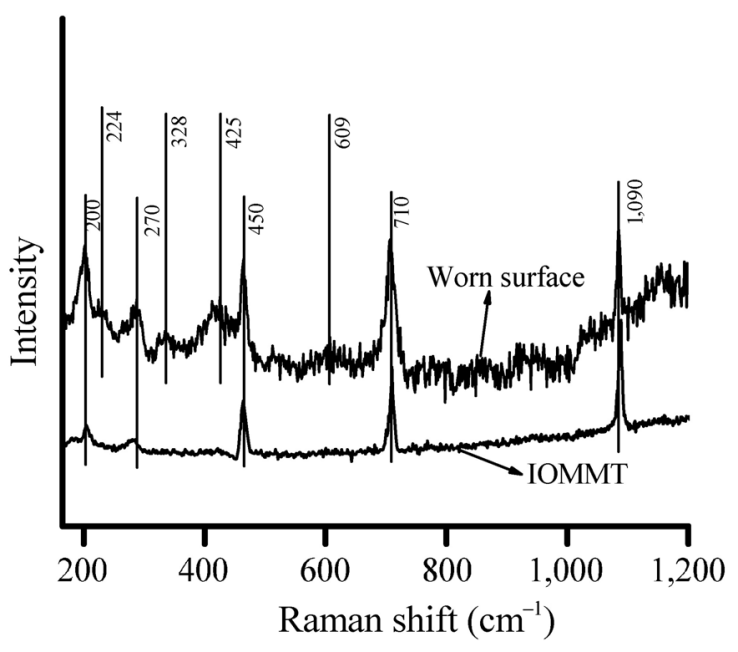

Fig. 10 Raman spectra of the nanometer IOMMT and worn surface lubricated with IOMMT grease at $200 \mathrm{~N}, 5 \mathrm{~Hz}$, and RT. 


\subsubsection{Tribological tests discussion}

Herein, the intricate lubrication behavior of the prepared insulating greases was studied for steel/steel friction pair with addition of 1.5\% IOMMT, which exhibited better tribological performances than that of the other greases. Figure 11 is a schematic of the nano-additive dispersed in the insulating greases during the sliding process, which can explain the friction and wear mechanisms. The friction reducing and anti-wear properties can be illustrated by the following factors. First, the crystal cell of nano-montmorillonite is similar to a sandwich structure; the upper and lower layers are silicon-oxygen tetrahedrons and the middle layer is an aluminum-oxygen octahedron [14-18]. The primary connection forces between the two layers are molecular and hydrogen bonds [44]. Under the friction heat, the connection forces are easily broken, leading nano-montmorillonite to release numerous small secondary particles and active oxygen. These secondary particles can act as spacers, preventing the close contact between the contact pairs [23,25]. Second, there is a large number of unsaturated and dangling bonds, such as $\mathrm{Si}-\mathrm{O}-\mathrm{Si}, \mathrm{O}-\mathrm{Si}-\mathrm{O}$, and $\mathrm{Mg}-\mathrm{O}$, existing on the nano-montmorillonite powder surface. It makes the particles possess strong polarity and adsorb tightly on the friction surface. Thus, the adsorption film possessing friction reducing and anti-wear properties is formed on the friction surface $[45,46]$. Third, the local high temperature and pressure caused by the asperity collision during the sliding process are beneficial for active atoms to be deposited and react, promoting the formation of an oxidation protecting film on the worn surface. At the same time, it can also induce decomposition and fracture of the lubrication oil chains to be deposited on the worn surface. These factors work together to generate the friction reducing and anti-wear properties [45, 47-49].

\section{Conclusions}

We summarize the abovementioned experimental works of insulating greases as follows: the inorganic modified nano-montmorillonite (IOMMT) as an insulating additive in the grease can significantly increase the number of electron traps to improve the AC breakdown voltage and volume resistivity. The insulating grease synthesized with IOMMT also exhibits better friction reducing and anti-wear performances for the steel/steel contact pairs, and the optimal concentration for IOMMT is recommended as $1.5 \mathrm{wt} \%$. The friction reducing and anti-wear performances are mainly attributed to the unique layered structure that prevents the close contact between the touching pairs and the protective tribofilm generated by the physical adsorption and chemical reaction. This indicates that IOMMT as a solid additive is highly effective to improve the insulation and tribological performances of lubricating greases for extensive applications.

\section{Acknowledgements}

This work is supported by the National Natural Science Foundation of China (No.51575181) and Beijing Natural Science Foundation of China (No. 51575181).

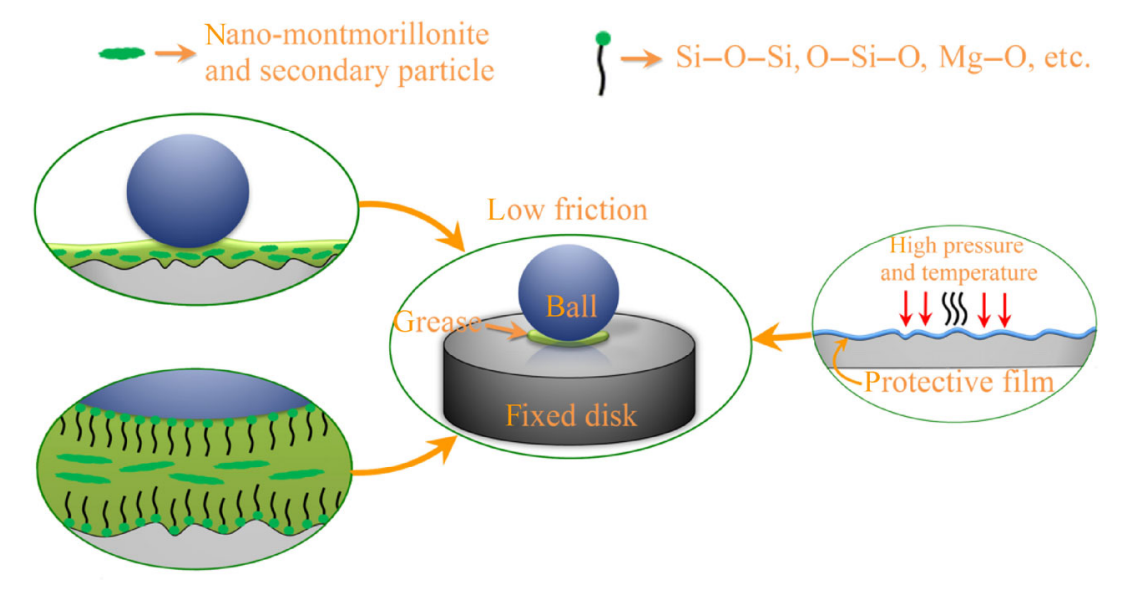

Fig. 11 Schematic of friction mechanism of the insulating greases. 
Open Access: The articles published in this journal are distributed under the terms of the Creative Commons Attribution 4.0 International License (http:// creativecommons.org/licenses/by/4.0/), which permits unrestricted use, distribution, and reproduction in any medium, provided you give appropriate credit to the original author(s) and the source, provide a link to the Creative Commons license, and indicate if changes were made.

\section{References}

[1] Waara P, Hannu J, Norrby T, Ake B. Additive influence on wear and friction performance of environmentally adapted lubricants. Tribol Int 34(34): 547-556 (2001)

[2] Qu J, Bansal D G, Yu B, Howe J Y, Luo H, Dai S, Li H, Blau P J, Bunting B G, Mordukhovich G, Smolenski D J. Antiwear performance and mechanism of an oil-miscible ionic liquid as a lubricant additive. Acs Appl Mater Interfaces 4(2): 997-1002 (2012)

[3] Piet M, Lugt. A review on grease lubrication in rolling bearings. Tribol Trans 52(4): 470-480 (2009)

[4] Ge X Y, Xia Y Q, Shu Z Y, Zhao X P. Conductive grease synthesized using nanometer ATO as an additive. Friction 3(1): 56-64 (2015)

[5] Ge X Y, Xia Y Q, Feng X. Influence of carbon nanotubes on conductive capacity and tribological characteristics of poly(ethylene glycol-ran-propylene glycol) monobutyl ether as base oil of grease. Trans ASME J Tribol 138: 0742-4787 (2015)

[6] Fan X Q, Xia Y Q, Wang L P. Tribological properties of conductive lubricating greases. Friction 2(4): 343-353 (2014)

[7] Fan X Q, Wang L P, Wen L, Wan S. Improving tribological properties of multialkylated cyclopentanes under eimulated epace environment: two feasible approaches. Acs Appl Mater Interfaces 7(26): 14259-14368 (2015)

[8] Fan X Q, Wang L P. Highly conductive ionic liquids toward high-performance space-lubricating greases. Acs Appl Mater Interfaces 6(16): 14660-14671 (2014)

[9] Voevodin A A, Zabinski J S. Nanocomposite and nanostructured tribological materials for space applications. Compos Sci Technol 65(5): 741-748 (2005)

[10] Marchetti M, Jones W R, Street K W, Wheeler D, Dixon D, Jansen M J, Kimura H. Tribological performance of some pennzane-based greases for vacuum applications. Tribol Lett 12(4): 209-216 (2002)

[11] Ge X Y, Xia Y Q, Cao Z F. Tribological properties and insulation effect of nanometer $\mathrm{TiO}_{2}$ and nanometer $\mathrm{SiO}_{2}$ as additives in grease. Tribol Int 92: 454-461 (2015)

[12] Hassan A M, Shahba R M A, Youssif M A, Youssif M A, Mazrouaa A M, Youssif M A E. Preparation of some dielectric greases from different types of polymers. J Appl Polym Sci 119(2): 1026-1033 (2011)

[13] Ferrito S J, Makal J M. Accelerated aging characteristics of lubricating greases used for separable insulated connector applications. In Transmission and Distribution ConferenceIEEE, 1999: 89-93.

[14] Zahed S, SharifiSanjani N. The role of clay-montmorillonite on thermal characteristics and morphology of electrospun PAN nanofibrous mats. E-Polym 11(18): 898-905 (2013)

[15] Yang T, Knutsson S. Swelling properties and permeability of expandable clays of potential use for nuclear waste disposal. J Earth Sci Geotech Eng 6: 49-61 (2016)

[16] Calvet R. Cation migration into empty octahedral sites and surface properties of clays. Clays Clay Miner 19(3): 175-186 (1971)

[17] Cheng M M, Song W J, Ma W H, Chen C C, Zhao J C, Lin J, Zhu H Y. Catalytic activity of iron species in layered clays for photodegradation of organic dyes under visible irradiation. Appl Catal B 77(3-4): 355-363 (2008)

[18] Lin F H, Chen C W, Kuo T F. Modified montmorillonite as vector for gene delivery. Biomaterials 27(17): 3333-3338 (2006)

[19] Usuki A, Kawasumi M, Kojima Y, Okada A, Kurauch T, Kamigaito O. Swelling behavior of montmorillonite cation exchanged for $\omega$-amino acids by-caprolactam. $J$ Mater Res 8(5): 1174-1178 (1993)

[20] Biswas M, Ray S S. Recent progress in synthesis and evaluation of polymer-montmorillonite nanocomposites. $A d v$ Polym Sci 155: 167-221 (1970)

[21] And K E S, Manias E. Structure and properties of poly (vinyl alcohol)/Na+ montmorillonite nanocomposites. Chem Mater 12(10): 2943-2949 (2000)

[22] Pojanavaraphan T, Schiraldi D A, Magaraphan R. Mechanical, rheological, and swelling behavior of natural rubber/montmorillonite aerogels prepared by freeze-drying. Appl Clay Sci 50(2): 271-279 (2010)

[23] Rashmi, Renukappa N M, Suresha B, Devarajaiah R M, Shivakumar K N. Dry sliding wear behaviour of organomodified montmorillonite filled epoxy nanocomposites using Taguchi's techniques. Mater Des 32(8-9): 4528-4536 (2011)

[24] Yuan Y, Liao R. A novel nanomodified cellulose insulation paper for power transformer. $J$ Nanomater 2014(17): 1-6 (2014)

[25] Fan B L, Yang Y L, Feng C, Ma J, Tang Y, Dong Y, Qi X W. Tribological properties of fabric self-lubricating liner based 
on organic montmorillonite (OMMT) reinforced phenolic (PF) nanocomposites as hybrid matrices. Tribol Lett 57(3): 1-12 (2015)

[26] Du Y F, Lv Y Z, Li C R, Chen M T, Zhou J Q, Li X X, Zhou Y, Tu Y P. Effect of electron shallow trap on breakdown performance of transformer oil-based nanofluids. J Appl Phys 110(10): 1-4 (2011)

[27] Du Y F, Lv Y Z, Li C R, Zhong Y X, Chen M T, Zhang S N, Zhou Y, Chen Z Q. Effect of water adsorption at nanoparticle-oil interface on charge transport in high humidity transformer oil-based nanofluid. Colloids Surf A 415(415): 153-158 (2012)

[28] Ravichandran J. Properties and catalytic activity of acidmodified montmorillonite and vermiculite. Clays Clay Miner 45(6): 1-7 (2014)

[29] Chi X H, Gao J G, Zhang X H. Electrical tree propagating characteristics of polyethylene/nano-montmorillonite composites. IEEE Trans Dielectr Electr Insul 22(3): 1530-1536 (2015)

[30] Wang H X, Wang H X, Xue L. Study of adsorption of industrial oil by expanded graphite. Carbon Tech 23: 21-23 (2004)

[31] Taguchi Y, Matsumoto T, Tokura Y. Dielectric breakdown of one-dimensional mott insulators $\mathrm{Sr}_{2} \mathrm{CuO}_{3}$, and $\mathrm{SrCuO}_{2}$. Phys Rev B 62(11): 7015-7018 (2000)

[32] Oka T, Aoki H. Ground-state decay rate for the Zener breakdown in band and mott insulators. Phys Rev Lett 95(13): 137601-137601 (2005)

[33] Liang Y, Chen Y X, Liu Y P. The development of the threeelectrode testing system for the volume resistivity of composite insulation materials. Sensors-Basel 10(3): 1-5 (2012)

[34] Rakowska A, Hajdrowski K. Influence of different test conditions on volume resistivity of polymeric insulated cables and polyethylene samples. In Dielectric Materials, Measurements and Applications, English International Conference-IEEE, 2000: 281-284.

[35] Huang J G, O'Sullivan F, Zahn M, Hjortstam O, Pettersson L A A, Liu R. Modeling of streamer propagation in transformer oil-based nanofluids. In Electrical Insulation and Dielectric Phenomena-IEEE, 2008: 361-366.

[36] Henry C H, Lang D V. Nonradiative capture and recombination by multiphonon emission in GaAs and GaP. Phys Rev B 15(2): 989-1016 (1977)

[37] Zhou J Q, Du Y F, Chen M T, Li C R, Li X X, Lv Y Z. AC and lightning breakdown strength of transformer oil modified by semiconducting nanoparticles. In Electrical Insulation and Dielectric Phenomena-IEEE, 2011: 652-654.

[38] Du Y F, Lv Y Z, Li C R, Chen M T, Zhou J Q, Li X X, Liu Tong. Insulating property and mechanism of semiconducting nanoparticles modified transformer oils. Proc Csee 32(10): 177-182 (2012)

[39] Zhang W, Xu M, Zhang X, Xie D R. Study of montmorillonite concentration on dielectric property and dispersion of crosslinked polyethylene/montmorillonite nano-composites. In Electrical Insulation and Dielectric Phenomena-IEEE, 2013: 531-534.

[40] Frost R L, Rintoul L. Lattice vibrations of montmorillonite: an FT Raman and X-ray diffraction study. App Clay Sci 11(2-4): 171-183 (1996)

[41] Xu K, Wang J, Xiang S, Chen Q, Zhang W D, Wang P X. Study on the synthesis and performance of hydrogels with ionic monomers and montmorillonite. App Clay Sci 38(s1-2): 139-145 (2007)

[42] Lübbe M, Gigler A M, Stark R W, Moritz W. Identification of iron oxide phases in thin films grown on $\mathrm{Al}_{2} \mathrm{O}_{3}(0001)$ by Raman spectroscopy and X-ray diffraction. Sur Sci 604(7-8): 679-685 (2010)

[43] Shim, Duffy SH/, Thomas S. Raman spectroscopy of $\mathrm{Fe}_{2} \mathrm{O}_{3}$ to $62 \mathrm{GPa}$. Am Mineral 87(2-3): 318-326 (2015)

[44] Hensen E J M, Tambach T J, Bliek A, Smit B. Adsorption isotherms of water in $\mathrm{Li}_{-}, \mathrm{Na}-$, and $\mathrm{K}$-montmorillonite by molecular simulation. $J$ Chem Phys 115(7): 3322-3329 (2001)

[45] Yu H L, Xu Y, Shi P J, Wang H M, Zhao Y, Xu B S, Bai Z M. Tribological behaviors of surface-coated serpentine ultrafine powders as lubricant additive. Tribol Int 43(3): 667-675 (2010)

[46] Frost R L, Cash G A, Kloprogge J T. Rocky Mountain leather, sepiolite and attapulgite-an infrared emission spectroscopic study. Vib Spectrosc 16(2), 173-184 (1998)

[47] Zhang B S, Xu Y, Xu B S, Gao F, Shi P J, Zhang B. The self-reconditioning effect of the phyllosilicate lubricating material on Fe-based tribopairs. J Funct Mater 42(7): 1301-1304 (2011)

[48] Yang Y, Gu J, Kang F, Kong X, Wei M. Surface restoration induced by lubricant additive of natural minerals. Appl Surf Sci 253(18): 7549-7553 (2007)

[49] Wang F. Research on microstructure of the auto-restoration layer of worn surface of metals. Mater Sci Eng A 399(1-2): $271-275$ (2005) 


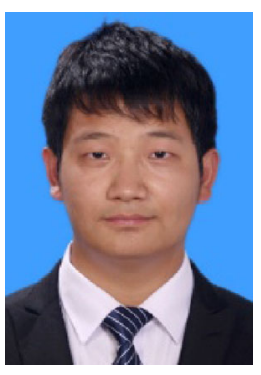

Zhengfeng CAO. He received his bachelor and master degrees from North China Electric Power University in 2013 and 2016, respectively.

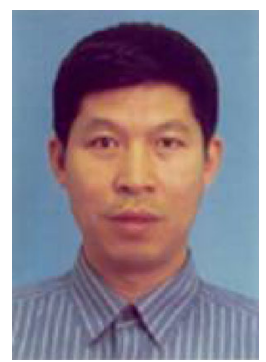

Yanqiu XIA. He received his PhD degree from Northeastern University in 1999, and was selected as Hundreds Talent Program of Chinese Academy of Science Professor in 2007. He joined the School of Energy
After that, he is currently a PhD student at the same university. His research interests are focused on preparation and tribological property investigation of lubricating greases.
Power and Mechanical Engineer, North China Electric Power University in 2010. His current position is a professor. His research areas cover tribology of mechanical and electrical equipment, focusing on lubricants, greases, additives, and tribochemistry. 